\title{
Financial Ignorance among Orthopedic Surgeons: A Survey In COVID-19 Era
}

\author{
Sachin Kale ${ }^{1}$, Ajit Chalak ${ }^{1}$, Sanjay Dhar ${ }^{1}$, Prasad Chaudhari ${ }^{1}$, Sushmit Singh ${ }^{1}$, \\ Aditya Gunjotikar ${ }^{1}$
}

\section{Abstract}

Background: COVID-19 pandemic has severely affected the finances of orthopedic surgeons around the globe due to recurring lockdowns and fewer elective surgeries. It has forced surgeons to reflect on their wealth management status and look for a second source of income as well.

Objectives: The objectives of the study were to determine the effect of the COVID-19 pandemic on the personal finances of orthopedic surgeons and gauge their knowledge regarding the stock market as a second source of income.

Methods: An online survey was conducted among the orthopedic surgeons practicing in Maharashtra, India. The survey included assessment of demographic data, financial knowledge, knowledge of the stock market, and wealth management status.

Results: Most respondents (75.6\%) were forced to think about the second source of income after the COVID-19 pandemic. Seventy-nine percent of surgeons felt the need for training for investment in stock markets.

Conclusion: Most of the respondents lack proper knowledge about funds management and retirement planning. This study indicates a strong need for formal education of orthopedic surgeons in the field of personal finance, stock markets, and retirement planning.

Keywords: COVID-19, orthopedic surgeons, personal finance.

\section{Introduction}

The COVID-19 pandemic has impacted orthopedic surgeons globally, especially during the initial phases of lockdown. There were guidelines to delay or postpone elective surgeries in all major private and government hospitals from the Ministry of Health and Family Welfare, Government of India. Due to a reduction in the number of elective surgeries, there has been a significant reduction in the income of the orthopedic surgeons who are involved in private practice. There were no definite timelines predicted for the end of lockdown in India as the number of COVID-19 cases was rising exponentially during the first 3 months of lockdown. As there was the uncertainty of the time frames for the restarting of the work, everyone had thought of another source of income, which included orthopedic surgeons as well.

\section{Methods}

This study was performed to analyze the effect of the COVID-19 pandemic situation on the income of orthopedic surgeons and their willingness to make the stock market the second source of income. A total of 28 questions that had multiple choices were asked. The questions covered the demographics of surgeons and were based on the individual profile, current knowledge on insurance, basics of the stock market, and mutual funds. The survey also enquired about their knowledge of compounding, inflation, and their willingness to gain more knowledge in personal finance.

The survey was distributed online through a Google Forms link through email and WhatsApp to orthopedic surgeons of Maharashtra, India. The responses were collected over a period of 1 month. All survey results were calculated as percentages out of the total responses and analyzed accordingly.

\section{Results}

A total of 457 orthopedic surgeons responded to the survey and gave their inputs. Eighty-two (45.3\%) of the respondents had experience of 5-15 years of orthopedic practice. Forty-seven (26\%) had 15-30 years, 31 (17\%) were

Address of Correspondence

Dr. Sushmit Singh,

Department of Orthopaedics, Dr. D Y Patil Medical College and Hospital, Nerul, Navi Mumbai, India. E-mail: drsushmits@gmail.com

Submitted Date: 23 Nov 2021, Review Date: 25 Nov 2021, Accepted Date: 26 Nov 2021 \& Published Date: 31 Dec 2021

Journal of Clinical Orthopaedics | Available on www.jcorth.com |DOI:10.13107/jcorth.2021.v06i02.442 This is an Open Access article distributed under the terms of the Creative Commons Attribution NonCommercial-Share Alike 4.0 License (http://creativecommons.org/licenses/by-nc-sa/4.0) which allows others to remix, tweak, and build upon the work non-commercially as long as appropriate credit is given and the new creation are licensed under the identical terms. 


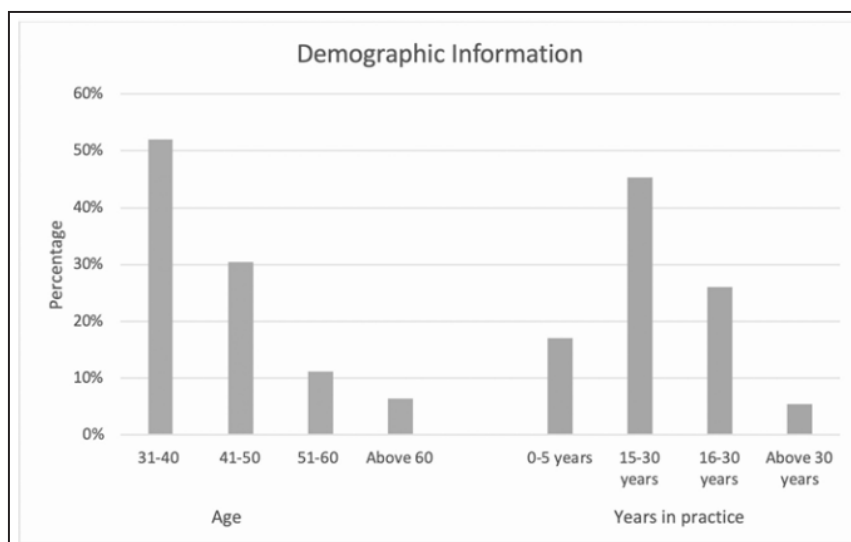

Figure 1: Demographic information of respondents of the survey highlighting their age and years in practice

trainees with $0-5$ years of experience, and $10(5.5 \%)$ had an experience of more than 30 years. Eleven (6\%) were postgraduate students. The majority of the respondents (45\%) were in the beginning phase of their orthopedic careers (Figure 1).

When asked if the COVID-19 pandemic has forced them to think about another source of income, a majority (75.6\%) of respondents agreed at the time of the survey. A majority (55.5\%) of the surgeons in the survey are investing in $<5$ years and almost $50.7 \%$ of the respondents are ready to save $11-30 \%$ of their income.

The majority of the respondents said that the stock market was a good source of income, while $11.4 \%$ of the surgeons considered it as gambling (Figure 2). About $54 \%$ of the surgeons thought of the stock market for investment purposes. About $79.3 \%$ of the surgeons feel the need for training for investment in the stocks markets which show a majority of the surgeons plan to manage their finances themselves and willingness to get trained. About $4.2 \%$ of the respondents plan to hire a fund manager or their wealth management.

In this survey, the majority (64.4\%) of orthopedic surgeons think that the stock market is a better option for investment as compared to fixed deposits. The majority $(40.3 \%)$ said that the stock market is a better option for investment while $17.4 \%$ said it's no better than mutual funds. About $64.4 \%$ of orthopedic surgeons considered the market inflation while planning their investment portfolio while $24.6 \%$ of the participants did not. Only $11 \%$ of the participants planned their retirement adequately (Figure 4). The rest of the orthopedic surgeons were taking insufficient actions for their retirement. A majority $(65.1 \%)$ of the respondents understand the power of compounding but have less knowledge of using it to their advantage. About $46.9 \%$ of orthopedic surgeons do not find themselves good in their wealth management while $22.6 \%$ never thought of it (Figure 3). About 27.6\% consider themselves good while only $2.9 \%$ of orthopedic surgeons consider themselves an expert.

\section{Discussion}

The extent of financial knowledge is quite limited among orthopedic surgeons. Orthopedic surgeons carry a vast amount of debt because of several sources such as educational loans, car and home loans, hospital loans, instrument loans, and credit card payments which are comparable to other fields of medicine as well $[1,2]$. The idea of this survey was to gauge the financial
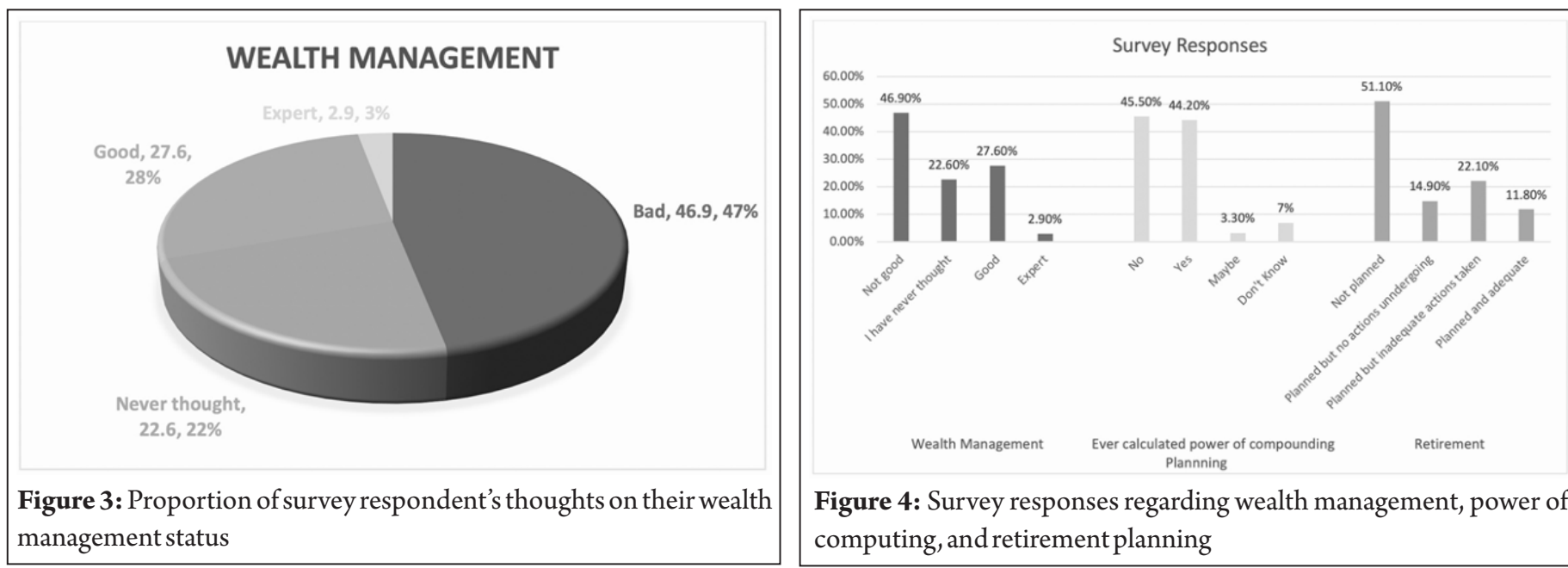

Figure 4: Survey responses regarding wealth management, power of computing, and retirement planning 
knowledge and status of orthopedic surgeons.

During the COVID-19 pandemic, 54\% of the respondents thought about the stock market which explains that there was a reduction in income through orthopedic practice in the initial phase of lockdown which demanded the surgeons to think of the second source of income.

Most of the respondents were ready to save a significant amount of their income and if it is invested in the stock market through proper planning and at regular intervals, a huge corpus can be made available for retirement and recreational purpose. Despite the knowledge of compounding as a big factor for investment, most of the respondents do not consider it during their investment. Time being a big factor for compounding, most of the respondents failed to reap the benefit as they started saving late in their career because of lack of financial training.

Fixed deposits have an average interest rate of 3-6\% while the stock market gives much higher returns as compared to them. However, due to a lack of knowledge and time, many surgeons end up taking the route of fixed deposits rather than other lucrative options. The majority of orthopedic surgeons do not know the difference between regular and direct mutual funds. If they are made to understand the difference, there will be an increase in the returns by about $1 \%$ in direct mutual funds which will make a significant difference in the long-term corpus creation. However, the fact is mutual fund managers ultimately invest the assets in the stock market for good returns. Hence, if an investment is done directly in the stock markets, one can expect good returns provided, they have the knowledge of the same.

There is no clear idea among surgeons about insurance and investment and many respondents have misinterpreted insurance as an investment option. The fact that Life Insurance Company gives only $6 \%$ long-term returns without much liquidity in the invested amount as compared to stock markets is unknown to many respondents as they consider it as a good investment.

Most orthopedic surgeons have their practice as the only source of income which hardly covers the substantial debt and prospects of future endeavors. COVID-19 pandemic and the subsequent lockdown further deteriorated this condition and forced a lot of orthopedic surgeons to rely on their savings and fall back on their repayments. The stock market has always been an option for investment and earning but many surgeons still consider it as gambling because of a lack of proper knowledge.

Even if the participants were not aware of managing their wealth themselves, the majority of them were aware of the term inflation. The basis of investment and returns is to beat the inflation of the market. This lack of financial literacy is further affecting their ability to manage personal finances and worsens their condition in such difficult times. Many surgeons and trainees suffer due to a lack of proper personal finance education during their formative years, and therefore, the majority of the respondents feel the need for such training.

The majority of them were aware of the terms such as inflation, compounding, and portfolio diversification but very few of them are managing their portfolio themselves.

According to the study, many orthopedic surgeons are not receiving adequate education in the field of finance due to the lack of such medical training. Orthopedic surgeons are already heavily burdened and the effects of that burden reach far beyond and affect not only short-term stress and fatigue but also future decisions regarding savings, loan repayment, and retirement planning. Initial education in financial planning and a second source of future funding contributes to better thinking and financial stability in the first phase of orthopedics $[3,4,5,6,7]$. Therefore, it is necessary for an hour to schedule a financial education drive among orthopedic surgeons. The medical curriculum should include other courses aimed at increasing the financial knowledge of surgeons so that they can manage their finances effectively. The importance of complex interest should be taught as soon as possible to new surgeons so that they can benefit and improve their financial situation significantly. Various decisions regarding health insurance and long-term life insurance should be made in the early days of a person's work and surgeons should be informed of this during their studies. Information on inflation, cofinancing, liquid investments, insurance, stock market, and real estate investments can go a long way in balancing the financial burden of new graduates and motivating them to have a secure and successful future as an orthopedic surgeon.

\section{Conclusion}

In a statewide survey of orthopedic surgeons, we found that surgeons do have interest in stock markets as a second source of income and this need has increased in the global pandemic scenario. Due to a lack of proper financial education, many orthopedic surgeons are not being able to take advantage of these alternative sources of income. In conclusion, providing basic financial education to orthopedic surgeons during their early years is important and can go a long way in reducing their financial burden and eventually making them better surgeons. 
Declaration of patient consent: The authors certify that they have obtained all appropriate patient consent forms. In the form, the patient has given his consent for his images and other clinical information to be reported in the Journal. The patient understands that his name and initials will not be published, and due efforts will be made to conceal his identity, but anonymity cannot be guaranteed.

Conflict of Interest: NIL; Source of Support: NIL

\section{References}

1. West CP, Shanafelt TD, Kolars JC. Quality of life, burnout, educational debt, and medical knowledge among internal medicine residents. JAMA2011;306:952-60.

2. Finney B, Mattu G. National family medicine resident survey. Part 1: Learning environment, debt, and practice location. Can Fam Physician 2001;47:117, 120, 126-8.

3. Jennings JD, Quinn C, Ly JA, Rehman S. Orthopaedic surgery resident financial literacy: An assessment of knowledge in debt, investment, and retirement savings. Am Surg 2019;85:353-8.

4. McKillip R, Ernst M, Ahn J, Tekian A, Shappell E. Toward a resident personal finance curriculum: Quantifying resident financial circumstances, needs, and interests. Cureus 2018;10:e2540.

5. Ramme AJ, Patel M, Patel KA, Montag WH, Schau AJ, Sabo SI, et al. Personal finance primer for the future orthopaedic surgeon: A starting point. JB JS Open Access 2021;6:e20.00006.

6. Cull WL, Katakam SK, Starmer AJ, Gottschlich EA, Miller AA, Frintner MP. A study of pediatricians' debt repayment a decade after completing residency. Acad Med 2017;92:1595-600.

7. Connelly $P$, List $C$. The effect of understanding issues of personal finance on the well-being of physicians in training. WMJ 2018;117:164-6.
Conflict of Interest: NIL

Source of Support: NIL

\section{How to Cite this Article}

Kale S, Chalak A, Dhar S, Chaudhari P, Singh S, Gunjotikar A. Financial Ignorance among Orthopedic Surgeons: A Survey In COVID-19 Era. Journal of Clinical Orthopaedics July-Dec 2021;6(2):08-11. 